\title{
Emotional intelligence, patterns for coping with decisional conflict, and academic achievement in cross-cultural perspective (evidence from selective Russian and Azerbaijani student populations)
}

\author{
Tatiana V. Kornilova ${ }^{a}$, Maria A. Chumakova ${ }^{b}$, Yulia V. Krasavtseva ${ }^{\text {a }}$ \\ ${ }^{a}$ Faculty of Psychology, Lomonosov Moscow State University, Moscow, Russia \\ ${ }^{\mathrm{b}}$ National Research University Higher School of Economics, Moscow, Russia \\ *Corresponding author. E-mail: julia.k7@gmail.com
}

Background. Choice, under conditions of uncertainty, is mediated by integral dynamic regulatory systems that represent hierarchies of cognitive and personality processes. As such, individual decision-making patterns can be studied in the context of intellectual and personality potential. This article presents the results of a cross-cultural comparison of personality characteristics, such as coping with uncertainty, emotional intelligence, and academic achievement, between Azerbaijani and Russian university students.

Objective. We aimed at establishing metric invariance and at highlighting relationships between emotional intelligence and the scales of the Melbourne Decision Making Questionnaire (MDMQ).

Design. Azerbaijani and Russian student samples were selected for this study due to the almost identical educational programs offered by Moscow State University to students in Moscow and its branch in Baku. Coping with uncertainty was measured by the MDMQ, emotional intelligence by the EmIn questionnaire, and academic achievement by GPA scores. Confirmatory factor analysis was used to verify factor structure invariance and congruence.

Results. The congruence of factor structures for both questionnaires was verified. For the MDMQ four-factor structure for both samples was confirmed. For the EmIn questionnaire, invariance for two scales was established - "Understanding other people's emotions" and "Managing own emotions". Relationships among personality traits, gender, age, and academic achievements are explained for the Lomonosov Moscow State University students in Moscow (Russia) and its branch in Baku (Azerbaijan). No crosscultural differences were found for emotional intelligence and productive coping (Vigi- 
lance). A cultural difference was established in unproductive coping preference for Buck Passing. A similarity between the cultures was captured in the relationship of higher emotional intelligence (EQ) scores to higher Vigilance scores and to lower levels of unproductive coping patterns. Vigilance was a predictor of academic achievement, but only in the Russian sample.

Conclusion. The similarity of the educational systems, as both samples studied similar programs, demonstrates very few cross-cultural differences.

Keywords: uncertainty, emotional intelligence, vigilance, buck passing, procrastination, GPA, Melbourne Decision Making Questionnaire (MDMQ)

\section{Introduction}

We conducted a cross-cultural comparison of: (a) EQ and individual decision-making patterns in Russian and Azerbaijani university student samples on the basis of congruence testing of the factor structures of two questionnaires - the Melbourne Decision Making Questionnaire and the "EmIn" questionnaire; and (b) the correlations of these psychological variables with academic achievement.

This comparison of the academic achievement correlations is justified by the fact that students of the Moscow State University branch in Baku studied identical programs and had the same teachers as the students in Moscow. Thus we controlled for the difference in educational systems that usually encumbers cross-cultural comparisons of student samples.

When talking about constructs with regard to which there are continuing disputes as to whether they "belong" to the cognitive or personality realm, the focus should be on the connections between those components of the intellectual and personality potential that could help shed light on the now "classical" idea of the unity of intelligence and affect. These constructs include emotional intelligence (EQ) (Salovey \& Mayer, 1990; Caruso \& Salovey, 2004). Further, we can add the individual patterns of decision making to these integrated formations, since a person's choice under conditions of uncertainty is mediated by the actual development of integral dynamic regulatory systems that represent hierarchies of both cognitive and personality processes (Kornilova, 2016a; Kornilova, Chumakova, Novikova, \& Kornilov, 2010).

To diagnose both EQ and individual characteristics of coping with uncertainty in decision-making, achievement tests and questionnaires are utilized. The latter usually give results that differ from "objective" tests. However, it is precisely the questionnaire results that permit discussion the interrelationships of these integrative properties as they are represented in an individual's self-awareness.

Attitude towards uncertainty has been regarded as one of the sources of crosscultural differences, as determined by the Hofstede index, allowing the differentiation between cultures more and less intolerant of uncertainty ${ }^{1}$. Based upon responses to three questions about the work in an organization, the index incorporated a rather broad generalization: "Uncertainty-avoiding cultures shun ambiguous situations. People in such cultures look for structure in their organizations, institu-

$1 \quad$ Hofstede defined culture as "a collective programming of the mind that distinguishes members of one group or category of people from another" (Hofstede, 2001, p. 9). 
tions, and relationships, which makes events clearly interpretable and predictable" (Hofstede, 2001, p. 148). This corresponds to an analysis of economic decisions and to comparisons of economic development levels of countries. However, it does not seem right to directly map cultural differences onto psychological differences. Keeping in mind the faultiness of such direct mapping, in our comparison of personality variables, we were able to describe cross-cultural differences between Russian and Azerbaijani students, relying on questionnaires that capture their tolerance and intolerance of uncertainty (Kornilova, Chumakova, \& Izmailova, 2015). In particular, greater intolerance of uncertainty was registered among the Azerbaijani men, while no cross-cultural differences were found among the women.

Another dimension of cultural differences, namely individualism vs. collectivism, was examined in a study of emotional intelligence (Pankratova, Osin, \& Lyusin, 2013). The Emotional Intelligence questionnaire, often shortened to "EmIn", was developed on Russian samples by D.V. Lyusin (2009), based on the SaloveyMayer-Caruso mixed model. Like many other questionnaires such as the SREIT (Self-Report Emotional Intelligence Test) (Schutte et al., 1998), "EmIn" measures subjects' notions of their EQ-related abilities. The Melbourne questionnaire was especially developed to measure individual decision-making patterns, and its factor structure was verified on Russian samples (Kornilova, 2013). Its scales reflect the style patterns of coping with uncertainty in decision making (DM). Our previous research permits us to assume the associations with each other of EQ and uncertainty attitudes, as well as their association with the academic achievements of students (Kornilova, \& Gadzhieva, 2016).

\section{Emotional Intelligence}

Approaches to understanding EQ as a cognitive ability on the one hand, and as a personality trait on the other, lie at the heart of many studies and measures. The relationship of EQ with a number of personality features, especially the Big Five traits, was discussed in the context of the Salovey-Mayer-Caruso mixed model applicability (Mayer, Salovey, \& Caruso, 2008). Bracket and Mayer (2003) demonstrated EQ correlations with the Big Five traits in the NEO-PI-R - neuroticism, extraversion, agreeableness, conscientiousness, and a moderate correlation with openness to experience. The relationship of Emotional Intelligence to academic intelligence and the Big Five has been discussed for a number of countries - for example, the Netherlands, Greece, Spain (e.g., Pérez-González \& Sanchez-Ruiz, 2014; Van der Linden, Tsaousis, \& Petrides, 2012; Van der Zee, Thijs, \& Schakel, 2002). EQ was a significant predictor of empathy (e.g., Imran, 2013).

Today, research is aimed at correlating EQ - as "hot" intelligence - not only with "cold" (verbal and nonverbal) intelligence, but also with memory and executive functions (Mayer et al., 2001; Schneider, Mayer, \& Newman, 2016). Multiple EQ connections were established with IQ (e.g., Husin, Santos, Ramos, \& Nordin, 2013; Kornilova, 2016a), with creativity (e.g., Averill, 2000; Ivcevic, Brackett, \& Mayer, 2007; Pavlova, \& Kornilova, 2016). Meanwhile, one of the leading pioneers in this field shifted from EQ to another construct - personal intelligence (Mayer, 2014). 
The data on the connections to academic success of students in different countries is rather inconclusive (Novikova \& Kornilova, 2013; Sanchez-Ruiz, Mavroveli \& Poullis, 2013), although the notion of a relationship among EQ, social success, and management was affirmed (Stain \& Buck, 2007; Caruso, 2016). H. N. Perera and M. DiGiacomo (2013) conducted a meta-analysis of research on EQ and student performance. However, no data was available on countries representing different cultures in which the students studied by common educational programs. We highlight precisely this aspect in our cross-cultural comparison of Russian and Azerbaijani students.

In Russian psychology, attention to the construct of EQ was due to both ideas of the unity of intelligence and affect with regards to the regulation of choice (Kornilova et al., 2010; Kornilova, 2016b), and to the successful development of EQ diagnostic tools that followed the popularization of the concept of multiple intelligences (e.g., Gardner, 2007). It was demonstrated on Russian samples that EQ is associated with such personality variables as self-evaluation of intelligence (at the level of self-awareness) (Novikova \& Kornilova, 2013), tolerance of uncertainty, and levels of autonomous morality (Kornilova \& Novototskaya-Vlasova, 2009; Kornilova, 2016a), intuitive style (Kornilova, Kornilov, 2013), "psychological reasonableness” (Novikova \& Kornilova, 2014), as well as cognitive strategies (Krasavtseva \& Kornilova, 2016; Kornilova, 2014).

The development of emotional intelligence research took place in the context of the undoubtedly positive nuances of this construct. Emotional culture was associated with the moral values of individuals, uniting them with humanity (Andreeva, 2009), and with the extent to which cultural differences (encompassed by the analysis of distal and proximal stimuli as conductors of cultural influence) can be reflected in the specifics of EQ relationships and the personality traits valued within certain societies.

Cross-cultural studies have established a higher level of emotional expression in countries with a higher level of individualism within the culture (Matsumoto, Yoo, \& Fontaine, 2008). However, no intercultural differences were found in the accuracy of emotion recognition (Soto \& Levenson, 2009). In a number of studies, the processes mediating cross-cultural differences in EQ were identified: For the individualistic culture of Germany, the balance between negative and positive emotions, measured by the SREIT, served as a mediator between life satisfaction and EQ, while for an Indian sample (a collectivistic culture), social support did (Koydemir, Şimşek, Schütz, \& Tipandjan, 2013). Greater accuracy of women in emotion recognition was noted for many cultures.

Russian colleagues tried to construct a single version of the questionnaire aimed at measuring EQ for Azerbaijani and Russian samples, but, in our opinion, they used a questionable procedure for merging the test data of students from the two countries into a single sample (Pankratova et al., 2013). We consider the procedure of establishing the factorial data structure congruence, as obtained by adapting psychological tools to different cultures, to be more reasonable (e.g., Kornilov, Kornilova, \& Grigorenko, 2016). 


\section{Advantages of Cross-Cultural Comparison of Azerbaijani and Russian Samples}

The reference to the cultural similarity of Azerbaijan, Iran, and Turkey due to their territorial proximity, common history, similar cultural traditions, religion (Islam), and language was the questionable criterion accepted by the authors of the above-mentioned comparison of EQ in Azerbaijani and Russian samples. Labeling Azerbaijani culture as "traditionalist" or "collectivistic" or tapping into other sociological clichés facilitates the schematization and simplification of understanding its members' psychological profile. A more important factor of cross-cultural differences could be the duality of general cultural conditions, stemming from seven decades that the inhabitants of Azerbaijan shared a common developmental path with the inhabitants of Russia. Now Azerbaijan is developing independently. In secular universities in the Republic of Azerbaijan, education tends to lean towards both European and Russian standards. In secondary school, education is conducted in two sectors - Russian and Azerbaijani - using the corresponding languages. Graduates from both sectors then enroll in universities.

The difference in educational systems within which the intellectual and personality potential of a person develops in different cultures, presents a challenge in cross-cultural studies. The existence of similar educational systems and institutions within the various countries in the post-Soviet space contributes to leveling this extremely significant factor. In particular, in the branches of Moscow State University (in Baku, Tashkent, and other cities), the educational process is based on similar programs, which allows cross-cultural validation of psychological diagnostic tools, promoting the development of psychological research in these countries.

Azerbaijani culture can be regarded as more collectivistic than Russian, and gender inequality remains a problem there, although the adoption of a relevant law testifies to the ongoing attempt to eliminate it (Soto \& Levenson, 2009). The observed high levels of Baku students' emotionality in comparison with that of Moscow students allows us to assume its large role in interpersonal communication. However, it is possible that we are talking about culturally accepted forms of self-expression, rather than emotional intelligence as such.

The conditions of university education are more uncertain than those of secondary school, and thus challenge students' independence. These conditions are included in a wider context of personal development within the cultural norms characterizing their life conditions. This broad context of individual attitudes toward uncertainty is recorded by the Melbourne Decision Making Questionnaire (MDMQ).

Our objectives were to test hypotheses of cross-cultural differences in EQ and individual features of decision-making regulation, represented by self-reports, among Azerbaijani and Russian samples, most of whom were students at Moscow State University. This would allow a differentiated approach to the discovery of relations between these individual personality characteristics and the academic achievements of the students. 
With this aim, we tested (a) the invariance of the factor structures of the MDMQ and EmIn questionnaires for the two compared samples; (b) differences in personality variables, reflecting individual decision-making features and attitudes towards uncertainty among Russian and Azerbaijani students; (c) their possible role as predictors of academic achievement.

\section{Methods}

\section{Samples and Design}

The study was conducted by psychological testing of two samples - Russian and Azerbaijani - and included three stages:

1. Establishing the factor structure invariance of the MDMQ for the two compared samples;

2. Establishing the factor structure invariance of the EmIn questionnaire for the two compared samples;

3. Cross-cultural comparison of psychological variables and an analysis of their correlation to GPA; identification of academic achievement predictors.

All students were tested individually or in small groups, with informed consent. The questionnaires were presented in Russian.

\section{First stage}

The initial sample for establishing the cross-cultural invariance of the MDMQ factor structures consisted of 521 people (374 women, 147 men), aged 16 to 66 $(\mathrm{M}=20.65, \mathrm{SD}=5.37)$. Of these, 252 people (161 women and $91 \mathrm{men})$ aged 16 to 23 were examined in Baku $(M=18.76, S D=1.41)$; in Moscow there were 269 people (213 women, 56 men) aged 18 to $66(M=22.43, S D=6.9)$. The groups differed significantly in age. To compare the indicators of the MDMQ scales, student-age participants studying at Moscow State University were selected from this sample (in the 18-25 age range).

The final sample for comparing the factor structure invariance included 416 people (309 women, 107 men). Of these, Baku students comprised 196 people (129 women and $67 \mathrm{men})$ aged 18 to $25(\mathrm{M}=19.27, \mathrm{SD}=1.16)$; Moscow students comprised 220 people ( 180 women, 40 men) aged 18 to $25(\mathrm{M}=19.75, \mathrm{SD}=1.18)$. The samples still differed significantly in age $(\mathrm{t}=-4.2142, \mathrm{df}=409.932, \mathrm{p}<0.001)$ and gen$\operatorname{der}\left(\chi^{2}=13.0672, \mathrm{df}=1, \mathrm{p}<0.001\right)$. Therefore, gender and age factors were taken into account as covariates when comparing the groups.

\section{Second stage}

The initial sample for establishing the factor structure invariance of the EmIn questionnaire included 1,078 people (761 women, $317 \mathrm{men}$ ), aged 16 to 69 ( $\mathrm{M}=22.79$, $\mathrm{SD}=8.06)$. Of these, Azerbaijani participants from Baku comprised 382 people $(260$ women and 122 men) aged 16 to $69(\mathrm{M}=21.62, \mathrm{SD}=9.18)$ and Russian participants from Moscow comprised 696 people (501 women, 195 men) between the ages of 17 and $68(\mathrm{M}=23.43, \mathrm{SD}=7.30)$. Samples differed significantly in age $(\mathrm{t}=-3.3083$, $\mathrm{df}=648.41, \mathrm{p}<0.001)$, but did not differ in the ratio of men and women $\left(\chi^{2}=1.6416\right.$, $\mathrm{df}=1, \mathrm{p}=0.200)$. 
The Azerbaijani sample comprised students from the university's so-called Russian sector, fluent in Russian.

\section{Third stage}

This stage included the definition of GPA (for most student participants) and correlation analysis of the relationship between academic success and the measured variables for which metric invariance was established. Regression analysis was conducted to identify the predictors of the students' academic achievement.

\section{Instruments}

\section{Melbourne Decision Making Questionnaire (MDMQ)}

The MDMQ was previously tested on Russian samples (Kornilova, 2013). It is based on the theoretical model of I. Janis and L. Mann (Janis \& Mann, 1977), according to which coping with a stressful situation generated by uncertainty includes a focus on risk awareness in the process of choosing the best of possible alternatives. When motivations are conflicted, individual tendencies in the regulation of choice arise, such as (a) productive coping (Vigilance - a careful, unbiased, and thorough evaluation of alternatives and rational decision making) and unproductive coping - (b) Buck Passing (leaving decisions to others and avoiding responsibility), (c) Procrastination (delaying decisions), (d) Hypervigilance (a hurried, anxious approach with untenable vacillation between alternatives) (Mann et al., 1997).

The 22 items of the questionnaire contain statements on the model of "When I make a decision, I ..." that the participant rates on a 3-point scale from "not true for me" to "true for me".

\section{Emotional Intelligence questionnaire - EmIn (Lyusin, 2009)}

The questionnaire is based on the concept of Salovey-Mayer-Caruso's EQ and includes 46 items with a 4-point scale from "completely disagree" to "completely agree".

Primary and secondary scales are then based on the answers. Two dimensions are defined: intrapersonal and interpersonal emotional intelligence and the ability to understand and manage emotions, which form the following scales:

1. Understanding own emotions: the ability to identify one's own emotions, verbally describe them, and understand the causes of the emotional state;

2. Understanding other people's emotions: the ability to recognize another person's emotions from non-verbal signals (facial expressions, gestures, tone of voice), sensitivity to the inner states of other people;

3. Controlling own emotions, including:

- Regulation of one's inner state: the ability to evoke and maintain the desired emotions and reduce the intensity of unwanted emotions;

- Control of expression: the ability to control the external manifestations of one's emotions;

4. Controlling other people's emotions: the ability to evoke other people's emotions, reduce the intensity of unwanted emotions. 


\section{GPA (Grade Point Average) - Average Academic Performance over the Last Three Semesters}

The international standard GPA was used to assess academic achievements. Despite the popularity of the average score in research within the field of education, some authors note its imperfection. For example, this type of research does not take into account grade inflation - the tendency to give higher scores for the same level of subject mastery at different levels of education or simply over time (Johnson, 1997). This affects the ability to compare the results of different student samples, and creates a "ceiling effect" when the average score of the sample approaches the upper bound of the grades. However, despite its shortcomings, grade point average is considered a scale with good reliability (Bacon \& Bean, 2006) and good criterial validity (Poropat, 2009), so it is rather successfully used as an indicator of academic achievement in most studies in the field of education.

\section{Results}

\section{Cross-Cultural Comparison of Coping with Uncertainty (Measured by MDMQ)}

\section{The MDMQ factor structure of the Azerbaijani sample}

We conducted a cross-cultural analysis for data concordance on the Azerbaijani and Russian samples.

For the Baku student sample testing results $(n=252)$, the factor structure of the questionnaire was verified, showing satisfactory characteristics of the initial fourfactor model: $\chi^{2}=313.949, \mathrm{df}=204, \mathrm{p}<0.001$; CFI=0.934; RMSEA $=0.046$ (CI RAMSEA for Moscow was 0.036 and 0.056). The factor load of one of the items (item 4 of the Vigilance scale) was insignificant; however, we did not exclude it from further calculations as it contributed to the value of the sample means.

Differences in individual characteristics of decision-making

For the cross-cultural comparison, individual values of latent variables were used, calculated based on the models with scalar invariance.

Comparison of the sample means showed no difference between the Moscow and Baku samples on the Vigilance scale; Buck Passing and Procrastination levels were higher for students in Moscow, and Hypervigilance was higher for students in Baku (see Figure 1).

Assuming the interaction of variables, we then used a multivariate analysis of variance (MANOVA) to identify cross-cultural differences. Dependent variables were the MDMQ scales; the independent variables gender, age, group (Baku or Moscow), and their interaction. Thus, the analysis tested the effect of seven variables (post hoc power 0.92).

For the Vigilance scale, no significant differences were found; that is, in this productive coping with uncertainty, Moscow and Baku students were similar. Differences were revealed for unproductive coping.

For Vigilance, no influence of the age factor was found; for the remaining scales (unproductive strategies in decision-making), a significant decrease in levels with age was found only in the Baku sample. 

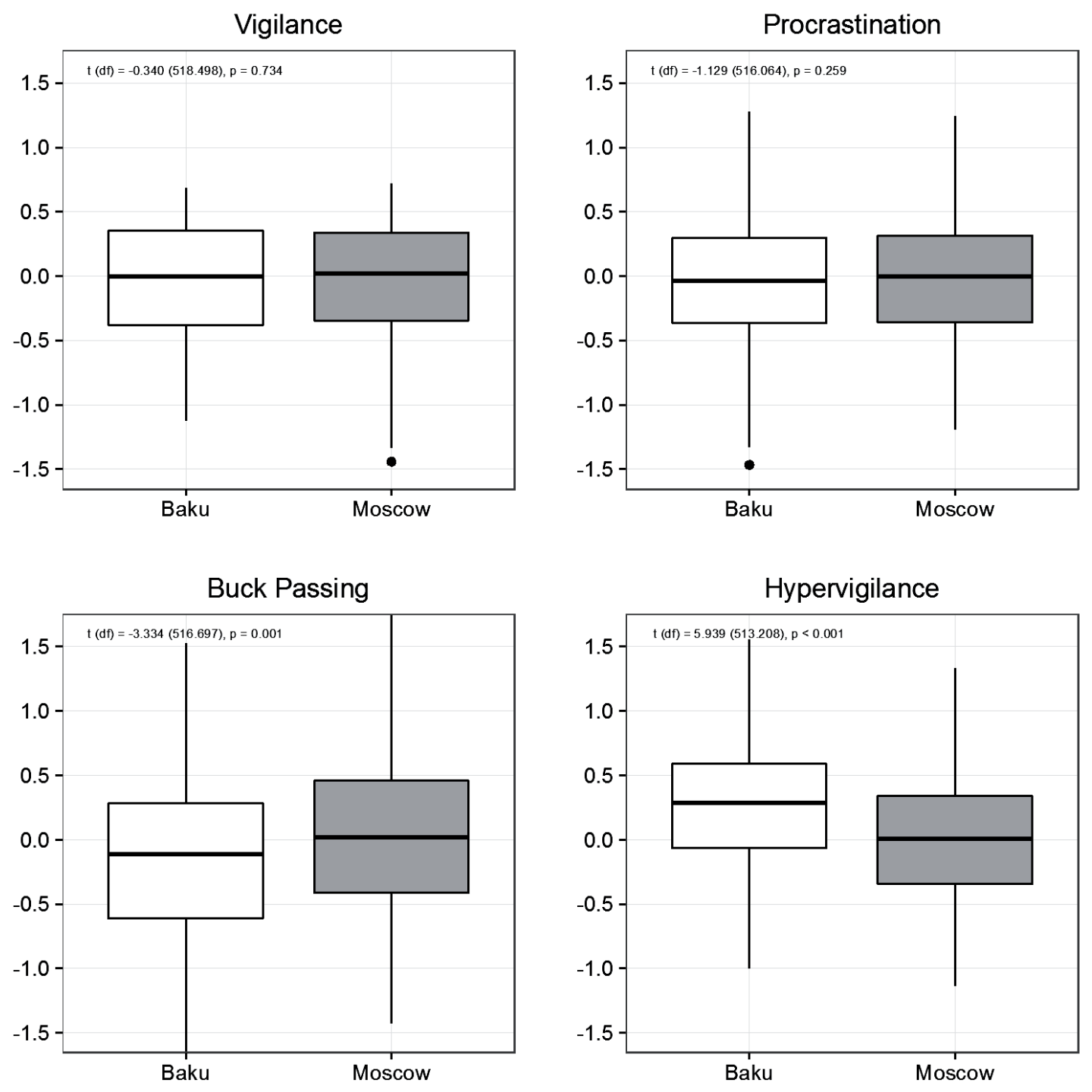

Figure 1. Differences in the individual tendencies of decision-making (according to the MDMQ) between student groups in Baku and Moscow. On the Y-axis is the score on the scale in the latent variable metric

For the Buck Passing scale, group factor influence was found ( $\mathrm{F}=15.604$, $\mathrm{p}<0.001$ ) - with a higher indicator for the Russian students (see Figure 1), as well as the interaction of age and group factors $(\mathrm{F}=6.969, \mathrm{p}=0.009)$. For the Procrastination scale, similar influence of the group factor $(\mathrm{F}=4.575, \mathrm{p}=0.033)$ and the interaction of age and group factors $(\mathrm{F}=9.197, \mathrm{p}=0.003)$ were shown.

For the Hypervigilance scale, which had a lower level in the Moscow sample, the influences of age $(\mathrm{F}=5.027, \mathrm{p}=0.025)$, group $(\mathrm{F}=10.660, \mathrm{p}=0.001)$, and their interaction $(\mathrm{F}=13.809, \mathrm{p}<0.001)$ were significant.

Specificity of the relationship between psychological variables as measured by MDMQ in Moscow and Baku students

In the Russian sample, the index of productive coping (Vigilance) was negatively associated with indices of unproductive copying - with Procrastination 
$(\mathrm{p}=0.001)$ and Hypervigilance $(\mathrm{p}=0.019)$, and in the Azerbaijan sample, with Buck Passing $(\mathrm{p}=0.026)$ and Procrastination $(\mathrm{p}=0.0001))$.

\section{Cross-Cultural Invariance of the EmIn Questionnaire Scales}

Initially, to establish the cross-cultural invariance of the EmIn questionnaire, we conducted a confirmatory factor analysis for the author's results (Lyusin, 2009) on the Moscow sample. The analysis was performed using the lavaan package for $\mathrm{R}$; the answers to the questionnaire items were considered ordinal variables. This model demonstrated low robustness indicators $(\chi 2=3427.951, \mathrm{df}=979, \mathrm{p}<0.001$, $\mathrm{CFI}=0.821, \mathrm{TLI}=0.811$, RMSEA $=0.060$ (90\% CI RMSEA 0.058 and .062 ), which

Table 1. Cross-cultural invariance for the EmIn questionnaire scales

\begin{tabular}{|c|c|c|c|c|c|c|c|}
\hline & $\chi^{2}(\mathrm{df})$ & CFI & TLI & $\begin{array}{l}\text { RAM- } \\
\text { SEA }\end{array}$ & $\begin{array}{l}\text { 90\% CI } \\
\text { RMSEA }\end{array}$ & $\begin{array}{c}\Delta \chi^{2}(\Delta) \\
\text { df })\end{array}$ & $\mathbf{p}$ \\
\hline \multicolumn{8}{|c|}{ Understanding other people's emotions } \\
\hline Original model Moscow & $\begin{array}{c}403.99 \\
(54)\end{array}$ & .937 & .923 & .097 & $\begin{array}{l}.088 \\
.105\end{array}$ & & \\
\hline $\begin{array}{l}\text { Modified model Moscow (cor- } \\
\text { relation of residual dispersions } \\
\text { were added for items } 42-46 ; \\
29-34 ; 38-42 ; 38-46 ; 32-42 \text { ) }\end{array}$ & $\begin{array}{c}143.62 \\
(49)\end{array}$ & .983 & .977 & .053 & $\begin{array}{l}.043 \\
.063\end{array}$ & & \\
\hline Model Baku & $\begin{array}{c}117.44 \\
(49)\end{array}$ & .962 & .949 & .061 & $\begin{array}{l}.047 \\
.075\end{array}$ & & \\
\hline Configural invariance & $\begin{array}{c}257.10 \\
(98)\end{array}$ & .979 & .972 & 0.055 & $\begin{array}{l}.047 \\
.063\end{array}$ & & \\
\hline Metric invariance & $\begin{array}{c}271.75 \\
(109)\end{array}$ & .979 & .974 & .053 & $\begin{array}{l}.045 \\
.061\end{array}$ & $\begin{array}{l}13.32 \\
(7.82)\end{array}$ & .094 \\
\hline Scalar invariance & $\begin{array}{c}308.32 \\
(132)\end{array}$ & .977 & .977 & .050 & $\begin{array}{l}.043 \\
.057\end{array}$ & $\begin{array}{c}6.29 \\
(18.75)\end{array}$ & .998 \\
\hline \multicolumn{8}{|l|}{ Controlling own emotions } \\
\hline Original model Moscow & $\begin{array}{c}152.93 \\
(14)\end{array}$ & .920 & .880 & .119 & $\begin{array}{l}.103 \\
.137\end{array}$ & & \\
\hline $\begin{array}{l}\text { Modified model Moscow (cor- } \\
\text { relation of residual dispersions } \\
\text { were added for items } 4-25 \text {; } \\
4-33 ; 25-33 \text { ) }\end{array}$ & $\begin{array}{c}58.17 \\
(11)\end{array}$ & .973 & .948 & .079 & $\begin{array}{l}.059 \\
.099\end{array}$ & & \\
\hline Model Baku & $\begin{array}{c}31.55 \\
(11)\end{array}$ & .950 & .904 & .070 & $\begin{array}{l}.042 \\
.099\end{array}$ & & \\
\hline Configural invariance & $\begin{array}{c}87.60 \\
(22)\end{array}$ & .970 & .943 & .074 & $\begin{array}{l}.058 \\
.091\end{array}$ & & \\
\hline Metric invariance & $\begin{array}{c}91.35 \\
(28)\end{array}$ & .971 & .957 & .065 & $\begin{array}{l}.050 \\
.080\end{array}$ & $\begin{array}{c}4.60 \\
(4.57)\end{array}$ & .409 \\
\hline Scalar invariance & $\begin{array}{c}137.16 \\
(41)\end{array}$ & .956 & .955 & .066 & $\begin{array}{l}.054 \\
.078\end{array}$ & $\begin{array}{c}14.27 \\
(130.04)\end{array}$ & .358 \\
\hline
\end{tabular}


prompted the decision to implement invariance modeling separately for each scale of the questionnaire.

The general design for establishing cross-cultural invariance for the EmIn scales included: Step 1) verification of the model on the Moscow sample; Step 2) correction of the model on the Moscow sample using the Lagrange indices; Step 3) verification of the final model from Step 2 on the Baku sample; Step 4) establishing configural invariance of the models in multi-group confirmatory factor analysis; Step 5) establishment of metric invariance of the models for our two samples; and Step 6) establishing scalar invariance for the two samples. The results are presented in Table. 1. For models obtained as a result of multi-group analysis (steps 4-6), the significance of changes in robustness indicators was also assessed. Table 1 summarizes the results for the scales that demonstrate cross-cultural invariance, in order to save space.

The scales Understanding other people's emotions and Controlling own emotions were applicable in the context of cross-cultural invariance. For these scales, the models obtained in the estimation of the configural invariance demonstrated satisfactory robustness indicators, and with the introduction of restrictions on the equality of factor loads and the equality of residual averages, the robustness indicators of the model did not change significantly.

\section{Cross-cultural differences in the scales of emotional intelligence}

The main result is the absence of significant differences in the EQ levels on invariant scales: $\mathrm{t}=0.384, \mathrm{df}=8930.052, \mathrm{p}=0.701$ for Understanding other people's emotions and $\mathrm{t}=0.895, \mathrm{df}=949.655, \mathrm{p}=0.371$ for Controlling own emotions (see Figure 2 ).

Significant differences were established in the gender factor for both EmIn scales and for the interaction of age and gender for the Controlling own emotions scale. In the whole sample, women scored higher on Understanding other people's emotions $(\mathrm{t}=2.291, \mathrm{df}=525.56, \mathrm{p}=0.022)$, and men scored higher on Controlling own emotions $(\mathrm{t}=-2.944, \mathrm{df}=581.669, \mathrm{p}=0.003)$. With age, women's Understanding other people's emotions increased, and men's decreased (see results of regression analysis in Table 2).

Table 2. Regression analysis of the effect of age on the EmIn scores of men and women

\begin{tabular}{ccccc}
\hline & \multicolumn{2}{c}{$\begin{array}{c}\text { Understanding } \\
\text { other people's emotions }\end{array}$} & \multicolumn{2}{c}{$\begin{array}{c}\text { Controlling } \\
\text { own emotions }\end{array}$} \\
\cline { 2 - 5 } & female & male & female & male \\
\hline F & 0.041 & 4.902 & 8.505 & 3.804 \\
$\mathrm{p}(\mathrm{F})$ & 0.839 & $\mathbf{0 . 0 2 8}$ & $\mathbf{0 . 0 0 4}$ & $\mathbf{0 . 0 5 2}$ \\
$\mathrm{df}$ & 759 & 315 & 759 & 315 \\
Adjusted $\mathrm{R}^{2}$ & 0.000 & 0.012 & 0.010 & 0.009 \\
$\beta($ Age) & 0.001 & $\mathbf{- 0 . 0 0 8}$ & $\mathbf{0 . 0 0 4}$ & $\mathbf{- 0 . 0 0 4}$ \\
$\mathrm{SE}(\beta)$ & 0.003 & 0.004 & 0.002 & 0.002 \\
$\mathrm{p}(\beta)$ & 0.839 & $\mathbf{0 . 0 2 8}$ & $\mathbf{0 . 0 0 4}$ & $\mathbf{0 . 0 5 2}$ \\
\hline
\end{tabular}

Note: Significant results are in bold italics. 

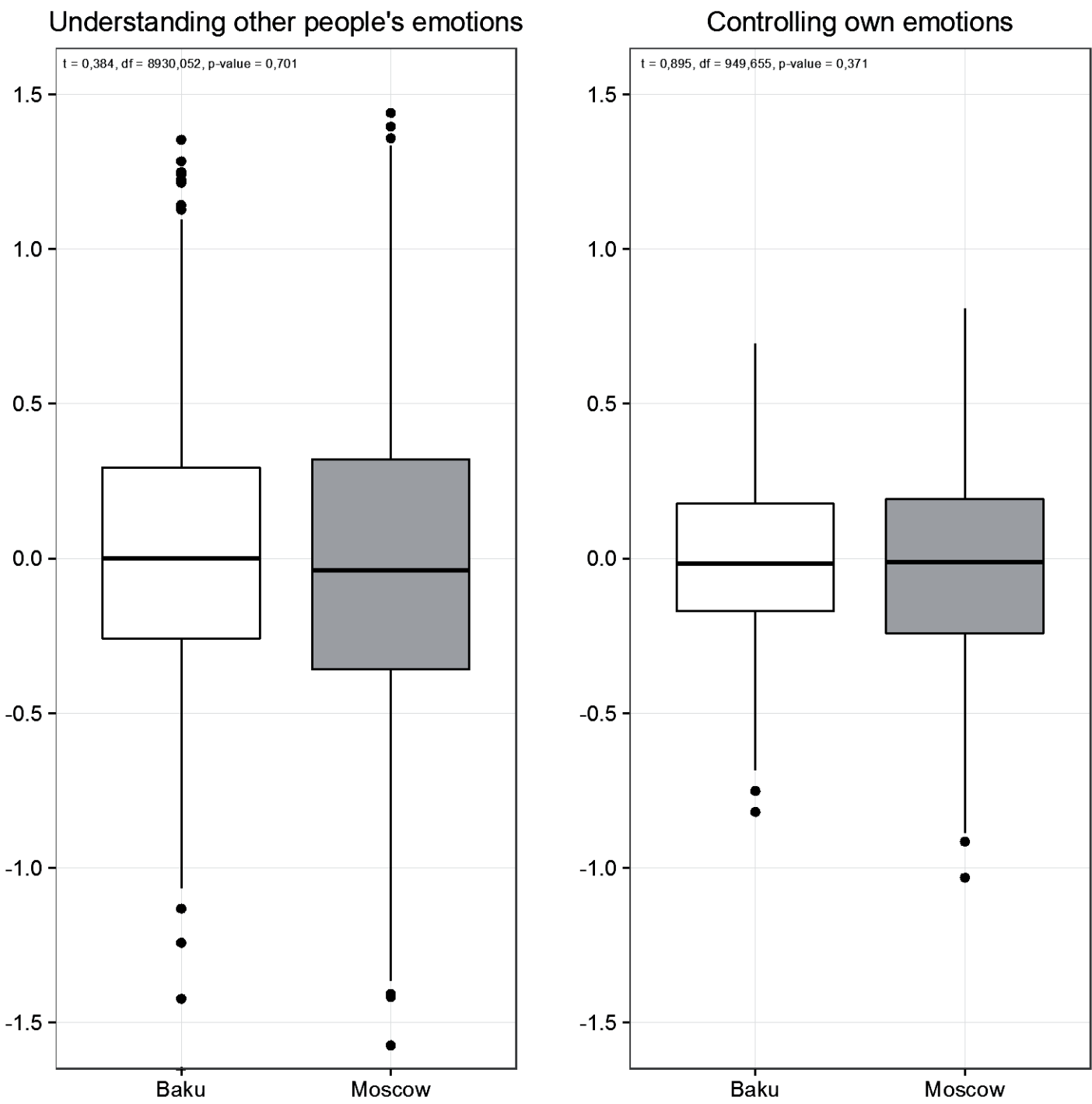

Figure 2. Comparison of sample averages of Azerbaijani and Russian samples (along the Y-axis is a scale score in the metric of latent variables)

Separately for each sample, a comparison of levels in men and women demonstrated that in the Baku sample, Understanding other people's emotions was significantly higher in women $(\mathrm{t}(\mathrm{df})=2.5527$ (208.587), $\mathrm{p}=0.011)$, and Controlling own emotions was higher in men ( $(\mathrm{df})=-1.9896(227.3), \mathrm{p}=0.048)$. In the Moscow sample, no significant differences were found in Understanding other people's emotions $(\mathrm{t}(\mathrm{df})=1.0971$ (313.004), $\mathrm{p}=0.273)$, and for Controlling own emotions, the same differences as in the Baku sample were observed: Men scored higher for this scale $(\mathrm{t}(\mathrm{df})=-2.1954$ (346.423), $\mathrm{p}=0.029)$. When comparing the indices for men in different samples, no differences were found on either EQ scale $(\mathrm{t}(\mathrm{df})=-0.6657$ (288.473), $\mathrm{p}=0.506$ and $\mathrm{t}(\mathrm{df})=0.3215$ (297.427), $\mathrm{p}=0.748)$. No significant differences were established when comparing the parameters for women either $(\mathrm{t}(\mathrm{df})=1.1339$ (608.234), $\mathrm{p}=0.257$ and $\mathrm{t}(\mathrm{df})=0.7118$ (647.864), $\mathrm{p}=0.477$ ). 


\section{Cross-Cultural Differences in Academic Performance and Personality Predictors of Academic Achievement}

Since GPA was not obtained for all students, the sample for cross-cultural comparison of academic achievement consisted of 274 people (208 women, 66 men), aged 16 to $28(\mathrm{M}=19.29, \mathrm{SD}=1.30)$. Of these, Baku students comprised 79 people (50 women and 29 men) aged 16 to $22(\mathrm{M}=18.48, \mathrm{SD}=1.33)$, and Moscow students comprised 195 people (158 women, $37 \mathrm{men})$ aged 18 to 28 ( $M=19.62$, $\mathrm{SD}=1.14)$.

In the identification of cross-cultural differences in academic achievement, multivariate variance analysis (MANOVA) was used. Academic achievement (GPA) was the dependent variable; gender, age, group (Baku or Moscow) and their interaction were the equivalent of the independent variables. Significant influence was established for the factors of age $(\mathrm{F}=20.156, \mathrm{p}<0.001)$, gender $(\mathrm{F}=24.871, \mathrm{p}<0.001)$, and $\operatorname{group}(\mathrm{F}=10.660, \mathrm{p}<0.001)$.

Achievement was significantly higher in the Russian students $(M=4.43$, $\mathrm{SD}=0.474$ for Moscow, $\mathrm{M}=3.62, \mathrm{SD}=0.686$ for Baku, $\mathrm{p}$-value ( $\mathrm{t}$-test $)<0.001$ ) in general, and in each sample it was higher in women (Figure 3 ).

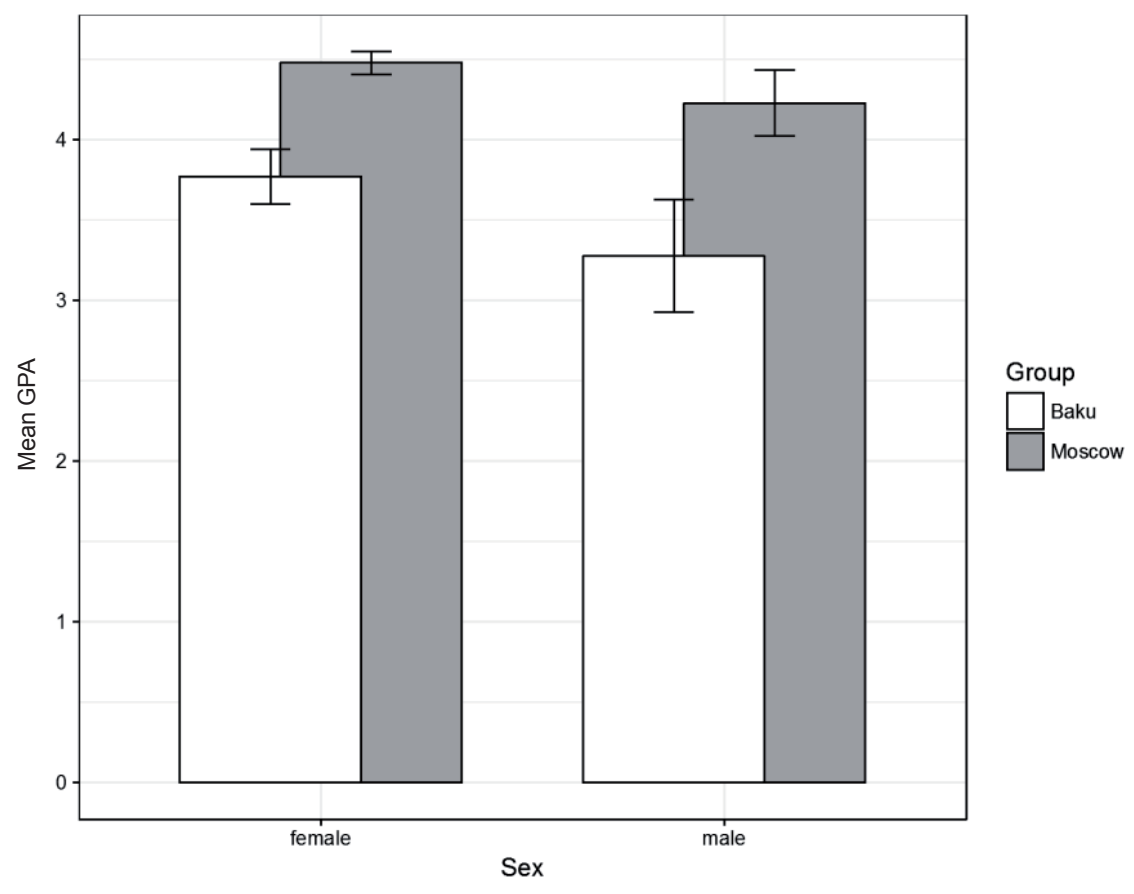

Figure 3. Gender differences in academic achievement (GPA) for Russian and Azerbaijani students

The correlation analysis of the relationship between personality traits and academic achievement demonstrated that Vigilance was significantly positively associated with academic achievement in the Russian sample $(\rho=0.18)$ and with both scales of emotional intelligence. In the Azerbaijani sample, academic performance was associated only with the Controlling own emotions scale $(\rho=0.24)$, and Vigilance was positively related to Understanding other people's emotions.

With the higher unproductive coping scores on the MDMQ, the levels of EQ are lower in all the samples (Table 3). 
Table 3. The interrelationships of gender, age, group (Baku or Moscow), and psychological variables, with academic achievement in the Baku and Moscow samples (below the diagonal - Baku; above the diagonal - Moscow; differing correlations are highlighted in bold)

\begin{tabular}{|c|c|c|c|c|c|c|c|c|c|}
\hline & & GPA & 1 & 2 & 3 & 4 & 5 & 6 & 7 \\
\hline & GPA & & .01 & -.02 & -.05 & $.18^{\star}$ & -.06 & -.10 & .01 \\
\hline 1 & Age & -.04 & & -.02 & -.02 & -.08 & .01 & .09 & .04 \\
\hline 2 & $\begin{array}{l}\text { Understanding other } \\
\text { people's emotions }\end{array}$ & .11 & .06 & & $.19^{\star *}$ & $.17^{\star}$ & $-.26^{* * *}$ & $-.29^{* * *}$ & $-.15^{\star}$ \\
\hline 3 & $\begin{array}{l}\text { Controlling own } \\
\text { emotions }\end{array}$ & $0.24^{\star}$ & -.10 & .06 & & $.18^{\star}$ & $-.28^{\star * *}$ & $-.30^{* * *}$ & $-.38^{\star * *}$ \\
\hline 4 & Vigilance & .08 & -.06 & $.24^{\star}$ & .14 & & $-.42^{\star * \star}$ & $-.41^{* * *}$ & .07 \\
\hline 5 & Buck Passing & .04 & -.08 & $-.27^{\star \star}$ & -.11 & $-.35^{\star \star \star}$ & & $.77^{\star * *}$ & $.59^{* * *}$ \\
\hline 6 & Procrastination & .01 & -.11 & -.19 & -.09 & $-.43^{* * *}$ & $.83^{* * *}$ & & $.68^{* * *}$ \\
\hline 7 & Hypervigilance & -.01 & -.14 & -.16 & -.13 & $-.34^{\star \star \star}$ & $.85^{\star \star *}$ & $.96^{\star * *}$ & \\
\hline
\end{tabular}

Regression analysis revealed only Vigilance as a predictor of academic achievement of students, as well as of gender and age (Table 4). EQ did not act as a predictor.

Table 4. Linear regression: dependent variable - academic achievement; independent variables - gender, age, group, MDMQ scales, EmIn scales

\begin{tabular}{lcccc}
\hline & Estimate & SE & t value & p \\
\hline Model 1 (F (df)=15.15 (262), $p<0.001$, adj $R=0.36)$ & & & & \\
Group & $\mathbf{0 . 7 0 8}$ & $\mathbf{0 . 0 9 3}$ & 7.577 & $<\mathbf{0 . 0 0 1}$ \\
Gender & $\mathbf{- 0 . 3 4 9}$ & $\mathbf{0 . 0 8 0}$ & $\mathbf{- 4 . 3 7 7}$ & $<\mathbf{0 . 0 0 1}$ \\
Age & 0.009 & 0.028 & 0.327 & 0.744 \\
Understanding of other people's emotions & -0.012 & 0.082 & -0.151 & 0.880 \\
Controlling own emotions & -0.071 & 0.131 & -0.541 & 0.589 \\
Gender x Understanding of other people's emotions & -0.013 & 0.147 & -0.086 & 0.931 \\
Gender x Controlling own emotions & -0.366 & 0.282 & -1.297 & 0.196 \\
Vigilance & $\mathbf{0 . 2 1 9}$ & $\mathbf{0 . 0 9 8}$ & $\mathbf{2 . 2 3 0}$ & $\mathbf{0 . 0 2 7}$ \\
Buck Passing & 0.030 & 0.091 & 0.326 & 0.745 \\
Procrastination & 0.008 & 0.134 & 0.059 & 0.953 \\
Hypervigilance & -0.072 & 0.132 & -0.544 & 0.587 \\
\end{tabular}




\begin{tabular}{lcccc}
\hline & Estimate & SE & t value & p \\
\hline Model 2 $(F(d f)=7.947(250), p<0.001$, adj $R=0.37)$ & & & & \\
Group & $\mathbf{0 . 5 0 1}$ & $\mathbf{0 . 1 8 7}$ & $\mathbf{2 . 6 7 1}$ & $\mathbf{0 . 0 0 8}$ \\
Gender & $\mathbf{- 0 . 3 4 3}$ & $\mathbf{0 . 0 8 2}$ & $\mathbf{- 4 . 1 8 4}$ & $<\mathbf{0 . 0 0 1}$ \\
Age & 0.018 & 0.041 & 0.443 & 0.658 \\
Understanding of other people's emotions & -0.020 & 0.082 & -0.243 & 0.808 \\
Controlling own emotions & -0.136 & 0.136 & -1.000 & 0.318 \\
Gender x Understanding of other people's emotions & -0.030 & 0.151 & -0.196 & 0.845 \\
Gender x Controlling own emotions & -0.331 & 0.290 & -1.141 & 0.255 \\
Vigilance & 0.335 & 2.467 & 0.136 & 0.892 \\
Buck Passing & -2.700 & 2.887 & -0.935 & 0.351 \\
Procrastination & -0.321 & 5.818 & -0.055 & 0.956 \\
Hypervigilance & 0.691 & 3.715 & 0.186 & 0.853 \\
Group x Vigilance & 3.939 & 3.010 & 1.309 & 0.192 \\
Group x Buck Passing & 2.633 & 3.654 & 0.721 & 0.472 \\
Group x Procrastination & 7.316 & 6.763 & 1.082 & 0.280 \\
Group x Hypervigilance & -7.993 & 4.839 & -1.652 & 0.100 \\
\hline
\end{tabular}

Factors of age and group in interaction with the MDMQ scores demonstrated influence only in the Moscow sample.

\section{Discussion}

Cross-cultural comparison of student samples did not establish differences in the levels of productive coping (Vigilance), but the samples did differ in the preference of the unproductive coping of Buck Passing as a tendency to avoid solving problems. As our additional research on the same samples demonstrated, with the measurement of tolerance and intolerance of uncertainty (Kornilov \& Bakhshaliyeva, 2016), the Buck Passing levels decreased with higher tolerance of uncertainty in the Azerbaijani students. Unexpected for this study were the links of growth of intolerance of uncertainty with the growth of Vigilance.

The age factor did not influence the Vigilance scores, but it positively influenced the reduction of unproductive coping with uncertainty in decision-making (on the MDMQ) in the Azerbaijani sample.

Comparison of sample averages in Vigilance coping permitted us to reject the hypothesis of cross-cultural differences and to affirm similar levels of positive coping with uncertainty to be an individual decision-making tendency, in both the compared samples. On the basis of a comparison of sample averages, we hypothesized that students in the Russian sample were more susceptible to such unproductive coping with uncertainty styles such as Procrastination and Buck Passing, and that students in the Azerbaijani sample were more inclined to Hypervigilance (as an untenable vacillation between alternatives). 
Factor structure congruence verification is an essential step that allows researchers to avoid artifacts, as the results of our cross-cultural study demonstrate. The fact that not only quantitative comparisons, but also interpretations, can be artifacts makes it even more pertinent. In our opinion, examples of this are the discussion of alleged differences in EQ between Russian and Azerbaijani students and the concept of "culture of shame" as applied to Azerbaijani culture (Benedict, 2005).

For data on the EmIn questionnaire on Russian and Azerbaijani samples, we established that only two scales are congruent: Understanding other people's emotions and Controlling own emotions; therefore, it was only correct to identify crosscultural differences on these scales. In both samples, these EQ variables correlate significantly with each other. Cross-cultural differences between the two samples on these metrically invariant scales were not established, which contradicts our colleagues' conclusion that "the representatives of Russian culture, in contrast to the representatives of Azerbaijani culture, have higher scores in understanding their own emotions and controlling them" (Pankratova et al ., 2013, p. 11).

Within-group differences in psychological variables were determined in both samples by gender/age factors and their interaction. The fact that women's scores on Understanding other people's emotions were higher corresponds to much of the cross-cultural data. The fact that Controlling own emotions increases with age in women, corresponds to the notions of socialization processes with age. However, the fact that men's scores on Controlling own emotions in both samples decrease with age, may indicate different requirements from society (allowing greater freedom of self-expression for men and requiring greater self-regulation for women). We do not discuss cross-cultural specifics in this context.

We have not confirmed the greater emotional restraint of Russian men (higher scores on Controlling own emotions) in comparison to Azerbaijani men, as was discussed in our Russian colleagues' article.

We established a similarity in the relations of productive coping (Vigilance) with the increase of EQ in both samples and the decrease of unproductive coping with the growth of EQ. This is generally consistent with the hypothesis of the positive role of EQ in the regulation of coping with uncertainty. Cross-cultural differences were that Vigilance was the predictor of academic achievement only in the Russian sample, although the relationship between the MDMQ and EmIn scales was similar in both samples. EQ did not affect student achievement.

As the results of the regression analysis demonstrated, Vigilance, as productive coping with uncertainty (which is a factor in students' independence), can contribute to improving academic performance. In this quality it is part of the self-regulation system among Russian students, but not among Azerbaijani students.

\section{Conclusions}

1. Cross-cultural invariance was established for all MDMQ scales, and the questionnaire can be applied to both Russian and Azerbaijani samples.

2. The factor structures congruence test for the EmIn questionnaire demonstrated only a partial similarity in the measurements of emotional intelligence in 
the two cultures - on the scales of Understanding other people's emotions and Controlling own emotions.

3. Cross-cultural comparison of student samples did not establish any differences in the levels of productive coping (Vigilance); however, the samples differed in the preference of unproductive coping - Buck Passing, as a tendency to avoid problem solving.

4. There were no differences between the Azerbaijani and Russian university students in the levels of EQ scales.

5. Cross-cultural similarity was established in the relationship between higher EQ scores with higher productive coping (Vigilance) indices and lower unproductive coping.

6. Vigilance was a predictor of academic achievement only in the Russian sample.

7. The EQ scores were not predictors of academic achievement.

8. The influence of age, gender, and cultural affiliation on academic achievement and their relationship to psychological variables was demonstrated (higher rates of achievement for Russian students, for girls in both samples, and for older students in the Russian sample).

\section{Limitations}

The first limitation of this study is the disproportion of men and women (158 women and 37 men in the Russian sample; 61 women and 36 men in the Azerbaijani sample). Therefore, the results concerning gender differences require further research. Secondly, the study was conducted in two capital cities (Moscow and Baku), which limits the generalizability of obtained results to Russian and Azerbaijani cultures in general. Thirdly, as most of the participants attended Moscow State University and its branch in Baku, the results of this study may be most applicable to students concerned with intellectual excellence and international integration. In order to achieve more robust results in cross-cultural research, the selected samples should include participants from a wider range of social groups.

\section{References}

Andreeva, I.N. (2008). O stanovlenii ponjatija 'ehmocional'nyj intellekt' [On the development of the 'Emotional Intelligence' concept]. Voprosy Psikhologii, 5, 83-95.

Averill, J.R. (2000). Intelligence, emotion, and creativity: From trichotomy to trinity. Handbook of emotional intelligence (pp. 363-376). San Francisco: Jossey-Bass.

Bacon, D.R., \& Bean, B. (2006). GPA in research studies: An invaluable but neglected opportunity. Journal of Marketing Education, 28(1), 35-42. https://doi.org/10.1177/0273475305284638

Benedict, R. (2005). The chrysanthemum and the sword: Patterns of Japanese culture. New York: Houghton Mifflin Harcourt.

Brackett, M.A., \& Mayer, J.D. (2003). Convergent, discriminant, and incremental validity of competing measures of emotional intelligence. Personality and Social Psychology Bulletin, 29(9), 1147-1158. https://doi.org/10.1177/0146167203254596

Caruso, D.R., \& Salovey, P. (2004). The emotionally intelligent manager: How to develop and use the four key emotional skills of leadership. San Francisco: John Wiley \& Sons. 
Imran, N., Aftab, M.A., Haider, I.I., \& Farhat, A. (2013). Educating tomorrow's doctors: A cross sectional survey of emotional intelligence and empathy in medical students of Lahore. Pakistan Journal of Medical Sciences, 29(3), 710. https://doi.org/10.12669/pjms.293.3642

Ivcevic, Z., Brackett, M.A., \& Mayer, J.D. (2007). Emotional intelligence and emotional creativity. Journal of Personality, 75(2), 199-236. https://doi.org/10.1111/j.1467-6494.2007.00437.x

Janis, I.L., \& Mann, L. (1977). Decision making: A psychological analysis of conflict, choice, and commitment. New York: Free Press.

Johnson, J.L. (1997). Commuter college students: What factors determine who will persist and who will drop out? College Student Journal, 31, 323-332.

Gardner, H. (2011). Frames of mind: The theory of multiple intelligences. New York: Basic Books.

Hofstede, G. (2001). Culture's consequences: Comparing values, behaviors, institutions and organizations across nations. Beverly Hills: Sage Publications.

Husin, W.N.I.W., Santos, A., Ramos, H.M., \& Nordin, M.S. (2013). The place of emotional intelligence in the 'intelligence taxonomy': crystallized intelligence or fluid intelligence factor? Procedia-Social and Behavioral Sciences, 97, 214-223. https://doi.org/10.1016/j. sbspro.2013.10.225

Kornilov, S.A., Kornilova, T.V., \& Grigorenko, E.L. (2016). The cross-cultural invariance of creative cognition: A case study of creative writing in US and Russian college students. New Directions for Child and Adolescent Development, 151, 47-59. https://doi.org/10.1002/ cad.20149

Kornilova, T.V. (2016). Intellektual'no-lichnostnyı potentsial cheloveka v usloviyakh neopredelennosti i riska. [The individual's intellectual and personality potential in uncertain and risky conditions]. SPb.: Nestor-Istoriya.

Kornilova, T.V. (2016). Mel'burnskij oprosnik prinjatija reshenij: russkojazychnaja adaptacija [Melbourne Decision Making Questionnaire: A Russian adaptation]. Psikhologicheskie Issledovaniya, 6(31), 4. Retrieved from http://psystudy.ru

Kornilova, T.V. (2016b). Psikhologija vybora kak myslitel'noe i lichnostnoe oposredstvovanie preodolenija neopredelennosti [Psychology of choice and decision making as cognitive and personality moderated overcoming of uncertainty]. Psikhologicheskii Zhurnal, 37(3), 113-124.

Kornilova, T.V. (2014) Tolerantnost' k neopredelennosti i jemocional'nyj intellekt pri prinjatii reshenij v uslovijah podskazki [Tolerance of uncertainty and emotional intelligence and the use of hints in decision-making]. Psychology. Journal of the Higher School of Economics, 4, 19-36.

Kornilova, T.V., \& Bakhshaliyeva, S.I. (2016). Kross-kul'turnoe issledovanie individual'nyh osobennostej prinjatija reshenij i tolerantnosti k neopredelennosti u rossijskih i azerbajdzhanskih studentov [A cross-cultural study of the relationship between decision making and tolerance of uncertainty in Russian and Azerbaijani students]. Psikhologicheskie Issledovaniya, 9(47), 2. Retrieved from: http://psystudy.ru

Kornilova, T.V., Chumakova, M.A., \& Izmailova, A.M. (2015, April). Implicit theories of intelligence and personality, attitudes towards uncertainty, and academic achievement in college students: Cross-cultural study. Paper presented at the 3rd International Academic Conference on Social Sciences (IACSS 2015), Istanbul, Batumi, 189-202.

Kornilova. T.V., Chumakova, M.A., Novikova, M.A., \& Kornilov, S.A. (2010) Psikhologiya neopredelennosti: Edinstvo intellektualno-lichnostnogo potenciala cheloveka [The psychology of uncertainty: Unity of human intellectual-personality potential]. Moscow: Smisl.

Kornilova, T.V., \& Gadjieva, G.I. (2016). Cross-cultural study of connection between the dark triad and emotional intelligence (for Russian and Azerbaijani samples). In V.V. Gritsenko (Ed.). Theoretical issues of ethnical and cross-cultural psychology: Proceedings of the Fifth In- 
ternational Scientific Conference 27-28 May 2016 in 2 vols.: vol. 1 (pp. 238-241). Smolensk: Smolensk Humanitarian University.

Kornilova, T.V., \& Novikova, M.A. (2013). Self-assessed intelligence, psychometric intelligence, personality, and academic achievement: Two structural models. In M. Gowda and A. Khanderia (Eds.). Educational achievement: Teaching strategies, psychological factors and economic impact (pp. 197-212). New York: Nova Science Publishers.

Kornilova, T.V., \& Novotockaja-Vlasova, E.V. (2009). Sootnoshenie nravstvennogo samosoznanija lichnosti, jemocional'nogo intellekta i prinjatija neopredelennosti [Levels of a person's moral self-awareness, emotional intelligence and tolerance of uncertainty]. Voprosy Psikhologii, 6, 61-70.

Koydemir, S., Şimşek, Ö. F., Schütz, A., \& Tipandjan, A. (2013). Differences in how trait emotional intelligence predicts life satisfaction: The role of affect balance versus social support in India and Germany. Journal of Happiness Studies, 14(1), 51-66. https://doi.org/10.1007/ s10902-011-9315-1

Krasavsteva, Y.V., \& Kornilova, T.V. (2016). Svojstva temnoj triady v reguljacii strategij prinjatija reshenij (na materiale igrovoj zadachi ajova - IGT) [The dark triad traits in the regulation of decision-making strategies]. Vestnik MGOU, 2, 22-33.

Lyusin D.V. (2009). Oprosnik na ehmocional'nyj intellekt EmIn: novye psihometricheskie dannye [The EmIn emotional intelligence questionnaire: New psychometric data]. In D.V. Lyusin \& D. V. Ushakov (Eds.). Socialnyy i ehmocionalnyy intellekt: Ot processov $k$ izmereniyam [Social and emotional intelligence: From processes to measurements] (pp. 264-278). Moscow: Institut psikhologii RAN.

Mann, L., Burnett, P., Radford, M., \& Ford, S. (1997). The Melbourne Decision Making Questionnaire: An instrument for measuring patterns for coping with decisional conflict. Journal of Behavioral Decision Making, 10(1), 1-19. https://doi.org/10.1002/(SICI)1099-0771(199703) 10:1<1::AID-BDM242>3.0.CO;2-X

Mayer, J.D. (2014). Personal intelligence: The power of personality and how it shapes our lives. New York: Farrar, Straus and Giroux.

Mayer,J.D.,Caruso,D.R., \& Salovey, P.(2016). The ability modelofemotionalintelligence:Principles and updates. Emotion Review, 8(4), 290-300. https://doi.org/10.1177/1754073916639667

Mayer, J.D., \& Salovey, P. (2001). Emotional intelligence as a standard intelligence. Emotion, 1(3), 232-242. https://doi.org/10.1037/1528-3542.1.3.232

Mayer, J.D., Salovey, P., \& Caruso, D.R. (2008). Emotional intelligence: New ability or eclectic traits? American Psychologist, 63(6), 503-517. https://doi.org/10.1037/0003-066X.63.6.503

Matsumoto, D., Yoo, S. H., \& Fontaine, J. (2008). Mapping expressive differences around the world: The relationship between emotional display rules and individualism versus collectivism. Journal of Cross-Cultural Psychology, 39(1), 55-74. https://doi.org/10.1177/0022022107311854

Novikova, M.A., \& Kornilova, T.V. (2014). Shkaly 'psikhologicheskoj razumnosti': aprobacija oprosnika na rossijskih vyborkah [The scales of 'Psychological Mindedness': Adaptation of a questionnaire to Russian samples]. Psikhologicheskij Zhurnal, 35(1), 63-78.

Pankratova, A.A., Osin, E.N., \& Lyusin, D.V. (2013). Osobennosti jemocional'nogo intellekta u predstavitelej rossijskoj i azerbajdzhanskoj kul'tur [Differences in emotional intelligence in Russian and Azerbaijani culture]. Psikhologicheskie Issledovaniya, 6(31), 11. Retrieved from http://psystudy.ru

Pavlova, E.M., \& Kornilova, T.V. (2016). The 'positive triad' of the regulation of personal choice among creative professionals. In G.B. Moneta \& E. Rogaten (Eds.). Psychology of creativity (pp. 153-166). New York: Nova Science Publishers. 
Perera, H.N., \& DiGiacomo, M. (2013). The relationship of trait emotional intelligence with academic performance: A meta-analytic review. Learning and Individual Differences, 28, 20-33. https://doi.org/10.1016/j.lindif.2013.08.002

Pérez-González, J.C., \& Sanchez-Ruiz, M.J. (2014). Trait emotional intelligence anchored within the Big Five, Big Two and Big One frameworks. Personality and Individual Differences, 65, 53-58. https://doi.org/10.1016/j.paid.2014.01.021

Poropat, A.E. (2009). A meta-analysis of the five-factor model of personality and academic performance. Psychological Bulletin, 135(2), 322. https://doi.org/10.1037/a0014996

Salovey, P., \& Mayer, J.D. (1990). Emotional intelligence. Imagination, Cognition And Personality, 9(3), 185-211. https://doi.org/10.2190/DUGG-P24E-52WK-6CDG

Sanchez-Ruiz, M.J., Mavroveli, S., \& Poullis, J. (2013). Trait emotional intelligence and its links to university performance: An examination. Personality and Individual Differences, 54(5), 658-662. https://doi.org/10.1016/j.paid.2012.11.013

Stein, S.J., \& Book, H. (2010). The EQ edge: Emotional intelligence and your success (Vol. 25). John Wiley \& Sons.

Schneider, W.J., Mayer, J.D., \& Newman, D.A. (2016). Integrating hot and cool intelligences: Thinking broadly about broad abilities. Journal of Intelligence, 4(1), 1. https://doi. org/10.3390/jintelligence4010001

Schutte, N.S., Malouff, J.M., Hall, L.E., Haggerty, D.J., Cooper, J.T., Golden, C.J., \& Dornheim, L. (1998). Development and validation of a measure of emotional intelligence. Personality and individual differences, 25(2), 167-177. https://doi.org/10.1016/S0191-8869(98)00001-4

Soto, J.A., \& Levenson, R.W. (2009). Emotion recognition across cultures: The influence of ethnicity on empathic accuracy and physiological linkage. Emotion, 9(6), 874. https://doi. org/10.1037/a0017399

Van der Linden, D., Tsaousis, I., \& Petrides, K.V. (2012). Overlap between general factors of personality in the Big Five, Giant Three, and trait emotional intelligence. Personality and Individual Differences, 53(3), 175-179. https://doi.org/10.1016/j.paid.2012.03.001

Van der Zee, K., Thijs, M., \& Schakel, L. (2002). The relationship of emotional intelligence with academic intelligence and the Big Five. European Journal of Personality, 16(2), 103-125. https://doi.org/10.1002/per.434

Original manuscript received June 26, 2017 Revised manuscript accepted January 22, 2018 First published online June 30, 2018 